\title{
Mediating Effect of Self-Leadership in the Relation between Job Commitment and Job Competence among Care Workers in Korea
}

\author{
Hee Kyung Kim \\ Professor, Department of Nursing, Kongju National University, Gongju, South Korea
}

\begin{abstract}
Background/Objectives: The purpose of this study is to provide basic data for nursing intervention development that enhances the job competence of care workers by exploring the mediating effect of selfleadership in the relationship between job commitment and job competence.

Method/Statistical analysis: Data were collected using a questionnaire targeting 96 care workers belonging to 5 home-based elderly welfare centers in D city. Data were analyzed by descriptive statistics, Pearson correlation coefficients, multiple regression and Sobel's test.

Findings: The care workers' job commitment scored 3.99 points, self-leadership scored 3.82 points, and job competence scored 3.95 points out of 5 points. The job competence of subjects was a high positive correlation with job commitment $(\mathrm{r}=.78, \mathrm{p}<.001)$, and self-leadership $(\mathrm{r}=.86, \mathrm{p}<.001)$. The main factor influencing the subject's job competence was self-leadership $(\beta=.75, p<.001)$, and $74.9 \%$ of job competence was explained. In addition, self-leadership had a complete mediating effect in the relationship between job commitment and job competence.

Improvements/Applications: Job commitment and self-leadership showed a high correlation with job competence, self-leadership had a complete mediating effect. Therefore, the directors should place importance on job-related factors of care workers. It is necessary to develop and operate a leadership improvement program to foster self-leadership.
\end{abstract}

Keywords: Job commitment, Self-leadership, Job competence, Care workers, Mediating effect.

\section{Introduction}

The influence of the elderly in Korean society is increasing continuously. More than half of the elderly in Korea evaluate their health as average or bad, and are suffering from the disease for more than 3 months, $89.5 \%$ of the elderly responded that they had chronic diseases diagnosed by a doctor, and the entire population of

\footnotetext{
Corresponding Author:

Hee Kyung Kim

Dept. of Nursing, Kongju National University, Gongju, South Korea

e-mail: hkkim@kongju.ac.kr
}

elderly people have an average of 2.7 chronic diseases, and $83.5 \%$ of elderly people have taken prescription drugs prescribed by doctors for more than 3 months. In addition, the physical and cognitive function of the elderly also has a higher rate of restriction as the age increases, and $71.4 \%$ of the subjects with reduced physical function appear to be receiving care ${ }^{[1]}$. Overall, there is a need for a systematic care service policy for the elderly.

$76.3 \%$ of the elderly in Korea currently live separately from their children, so the demand for homevisit care services provided by care workers is expected to continue to increase ${ }^{[1]}$ and the elderly prefer to receive care at home, and the family is hoped that caregivers will visit home and provide services. Accordingly, the care 
service providers for the elderly under the long-term care insurance for the elderly in Korea are care workers, and the job competence of care workers can be evaluated in terms of service quality. Job competence is an action that leads to successful outcomes through interaction with behavioral characteristics observed from those who generate high performance, that is, knowledge, skills, attitudes, and values ${ }^{[2]}$. In particular, in the case of care workers since their competence plays an even more important role in the health and well-being of the subject.

According to the research to date, it has been said that if care workers have excellent competence, expertise and skill, they can satisfy the needs of recipients and provide quality services ${ }^{[3]}$. In the case of 123 care workers job competence was about 3.66 out of 5 points ${ }^{[4]}$ and as a result of measuring the job competence of 116 care workers, it was 3.79 out of $5^{[5]}$ and it needs to be made so that they have higher job competence. In order to increase the job competence of these care workers, it is necessary to analyze the factors that affect job competence improvement.

In this study considers the results that the degree of commitment to one's job affects job performance ${ }^{[6]}$, and leadership affects job competence and performance ${ }^{[7]}$. Job commitment means that one's job becomes the center of one's life, the desire to actively participate in the job becomes stronger, and the job is the standard in the process of establishing and realizing the concept of self ${ }^{[8]}$ and it is the degree to which he is immersed in his current job based on specific beliefs about the relationship between himself and his current job ${ }^{[9]}$. Immersion is a result of the ability to experience ${ }^{[10]}$ and this level of job commitment appears more strongly in performancerelated situations and situational characteristics.

On the other hand, self-leadership can be said to be able to exercise leadership by controlling and managing thoughts and actions with one's own autonomy ${ }^{[11]}$. According to a study, the self-leadership of 311 daycare center teachers was a major factor influencing teacher competency ${ }^{[7]}$ and as it was found that childcare teachers with high self-leadership have higher awareness of expertise and more positive verbal interactions ${ }^{[12]}$, it is inferred that it will have a major impact on enhancing the job competence of care workers.

Therefore, the purpose of this study is to empirically test the mediating effect of self-leadership in the relationship between job commitment and job competence and provide basic data for developing strategies to increase the job competence of care workers.

\section{Method}

1. Subjects: The subjects of this study were 96 care workers in charge of home-visit care belonging to 5 home-based elderly welfare centers of D city, who were adult men and women who understand the purpose of the study and voluntarily expressed their willingness to participate and gave written consent, who were care workers with more than 6 months of job experience. The number of subjects was calculated using the G-power 3.1.9.4 program. The number of samples required to maintain 2 predictors, effect size of .15 , significance level of .05 , and power of .90 was 88 , and 96 people were surveyed considering the dropout rate of $10 \%$.

\section{Instruments}

2.1. Jobcommitment: A job commitment tool revised by Park $^{[6]}$ was used. This tool has a total of 9 questions, and on a Likert 5-point scale, the higher the score, the higher the degree of job commitment. In the study by Park ${ }^{[6]}$, the reliability was Cronbach's $\alpha=.92$. In this study, it was .90.

2.2. Self-leadership: A self-leadership tool revised by $\mathrm{Koh}^{[13]}$ was used. There are 20 questions. On a Likert 5-point scale, the higher the score, the higher the degree of self-leadership. In Koh's study, the reliability of the sub-area was Cronbach's $\alpha=0.78 \sim 0.86$. In this study, it was .94.

2.3. Job Competence: A tool reconfigured by Lee ${ }^{[14]}$ from National Competency Standards for care workers was used. There are 24 questions. On a Likert 5-point scale, the higher the score, the higher the degree of job competence. At the time of development, the reliability Cronbach's $\alpha=.85$. In this study, it was .94 .

3. Data collection: Data collection was from July to August 2020. Researchers and research assistants visited5 home-based elderly welfare centers in D city, and after receiving permission by explaining the research purpose and method to the center director, after meeting, the research purpose was explained directly to the nursing care provider and received a written consent with the help of a research assistant, especially in the data collection method. After that, data was collected through completing 
questionnaires. The time required to complete the questionnaire was 15 minutes.

4. Ethical consideration: This study was approved by the institutional review board of $\mathrm{K}$ University after submitting a proposal for ethics of the subject for deliberation (KNU_IRB_2020-44). The code of ethics was followed.

5. Data Analysis: Using the SPSS Window 23.0 program, the degree of variables of care workers was calculated by descriptive statistics, the correlation between job commitment, self-leadership and job competence was calculated using Pearson's correlation coefficients, and the mediating effect was obtained using multiple linear regression, and the significance test for the mediating effect size was analyzed with the Sobel's test.

\section{Result and Discussion}

1. General characteristics of subjects: The subjects of this study were care workers in charge of homevisit care $(100 \%)$, and the age ranged from 32 to 76 years old, with an average of $57.78 \pm 8.89$ years old, with age over 60 years accounting for $44.8 \%$ (44) over 60 years old. Most (96.9\%) were women, and the most frequent education level was high school graduate with $48.9 \%$ (44), and the average work experience as a care worker was $42.59 \pm 31.82$ months, ranging from 7 months to 11 years. It was found that more than half $(69.4 \%, 77)$ had no other licenses other than the care worker license. Most of them $(74.4 \%)$ received less than 1 education session during the past year, and for the monthly income, 0.51-1 million won accounted for more than half $(55.2 \%)$.

2. Degree of Job commitment, Self-leadership and Job Competence in Care workers: The care workers' job commitment scored 3.99 points out of 5 points, self-leadership scored 3.82 points out of 5 points, and job competence scored 3.95 points out of 5 points [Table 1].

Table 1. Degree of Job Commitment and Selfleadership on Job Competence in Care Workers $(\mathrm{N}=96)$

\begin{tabular}{|l|c|c|}
\hline Variables & $\mathbf{M} \pm$ SD & Range \\
\hline Job commitment & $3.99 \pm 0.61$ & $1 \sim 5$ \\
\hline Self-leadership & $3.82 \pm 0.48$ & $1 \sim 5$ \\
\hline Job competence & $3.95 \pm 0.46$ & $1 \sim 5$ \\
\hline
\end{tabular}

3. Correlation between job commitment, selfleadership and job competency in subjects: Job competence and job commitment $(\mathrm{r}=.78, \mathrm{p}<.001)$, job competence and self-leadership $(\mathrm{r}=.86, \mathrm{p}<.001)$, and self-leadership and job commitment $(\mathrm{r}=.86, \mathrm{p})$ $<.001$ ) of subjects showed high positive correlations [Table 2].

Table 2. Correlation between Job Commitment, Self-leadership and Job Competence in Subjects

\begin{tabular}{|l|c|c|c|}
\hline Variables & Job commitment r(p) & Self-leadership r(p) & Job competence r(p) \\
\hline Job commitment & 1 & & \\
\hline Self-leadership & $.86(<.001)$ & 1 & \\
\hline Job competence & $.78(.025)$ & $.86(<.001)$ & 1 \\
\hline
\end{tabular}

4. Mediating effects of self-leadership in the relation between job commitment and job competence in subjects: As a result of examining the multicollinearity, the Durbin-Watson index for autocorrelation was 1.96 , which was close to 2, which was independent. The multicollinearity between the independent variables was less than 10 with a VIF (Variance Inflation Factor) index of 3.90, and the tolerance was 0.26 , which was higher than the standard value of 0.1 , indicating that there was no multicollinearity, so this data was suitable for regression analysis.

Self-leadership, a parameter between job commitment and job competence, had a significant influence in the regression analysis in step 3.

As a result of the regression analysis of step 1, job commitment, an independent variable, had a statistically significant effect on self-leadership, a mediating variable $(\beta=.86, \mathrm{p}<.001)$, and the explanatory power to 
explain self-leadership was 74.4\%.In step 2 regression analysis, job commitment, an independent variable, had a significant effect on job competence, a dependent variable $(\beta=.78, \mathrm{p}<.001)$, and the explanatory power to explain job competence was $60.4 \%$.To test the effect of self-leadership as an intermediary variable on job competence as a dependent variable in step 3, as a result of regression analysis with job commitment and selfleadership as predictive factors and job competence as the dependent variable, job commitment $(\beta=.13, p=.211)$ was not significant, but self-leadership $(\beta=.75, p<.001)$ was a significant predictor of job competence.

As a result of comparing the $\beta$ values, it was found that self-leadership was completely mediated since .78 in step 2 was greater than .13 in step 3 , and job commitment in step 3 was not statistically significant. The degree to which self-leadership explains job competence was $74.9 \%$.As a result of conducting Sobel's test to confirm the significance of the mediating effect coefficient, it was statistically significant $(\mathrm{Z}=7.14, \mathrm{p}<.001)[$ Table 3$]$.

Table 3. Mediating effects of self-leadership in the relation between job commitment and job competence

\begin{tabular}{|c|c|c|c|c|c|c|c|}
\hline Variables & B & $\boldsymbol{\beta}$ & $\mathbf{t}$ & p & $\operatorname{Adj} . \mathbf{R}^{2}$ & $\mathbf{F}$ & p \\
\hline Step 1: Job commitment $\rightarrow$ Self-leadership & .68 & .86 & 16.52 & $<.001$ & .741 & 272.82 & $<.001$ \\
\hline Step 2: Job commitment $\rightarrow$ Job competence & .59 & .78 & 11.99 & $<.001$ & .600 & 143.67 & $<.001$ \\
\hline Step 3: Job commitment, Self-leadership & & & & & .744 & 138.95 & $<.001$ \\
\hline \multicolumn{8}{|l|}{$\rightarrow$ Job competence } \\
\hline 1. Job commitment $\rightarrow$ Job competence & .09 & .13 & 1.26 & .211 & & & \\
\hline 2. Self-leadership $\rightarrow$ Job competence & .72 & .75 & 7.33 & $<.001$ & & & \\
\hline $\mathrm{Z}=7.14, \mathrm{p}<.001$ & & & & & & & \\
\hline
\end{tabular}

\section{Discussion}

This study was attempted to understand the mediating effect of self-leadership in the relationship between job commitment and job competence.

The job commitment of this study was 3.99 out of 5 points, which was higher than the level of job commitment of 3.82 points $^{[6]}$ as a result of a survey of employees who received job training in securities companies. The life of care workers serving and providing care to others can be regarded highly as a desirable job in the profession and needs to be supported so that it can be further improved. The self-leadership score was 3.82 out of 5, somewhat higher than the self-leadership of the daycare center teachers which was $3.75^{[7]}$. Self-leadership is a way of thinking about yourself and your role in what you're doing, and care workers have a professional sense of duty to take the lead in helping the vulnerable subjects and it is judged that they have the ability to perform their role as a leader. In the future, if education to improve such leadership is given, it can be further improved. Also, the job competence of care workers was 3.95 out of 5 , which was slightly higher than that of 3.68 points of job competence of 217 care workers who provide homevisit care services with more than 1 month's experience [15]. The results of this study are considered to be the result of having subjects with higher job competency as they were subjects who provided nursing services for more than 6 months.

The relationship between the subject's job competence, job commitment, and self-leadership showed a high positive correlation. This was similar to the result ${ }^{[16]}$ showing a positive correlation between the job commitment of the cabin crew of a low-cost airline and 3 sub-areas of job competence. In addition, the self-leadership of daycare center teachers showed a positive correlation with the teaching competence, which is consistent with the result ${ }^{[7]}$ that the higher the self-leadership, the higher the teaching competency. Therefore, it is recommended to consider job commitment and self-leadership in education and activities to increase the job competence of care workers. Also, in the relationship between job commitment and job 
competence, self-leadership had a complete mediating effect. This was similar to the result of a study of care workers ${ }^{[17]}$ showing that self-leadership improves the service quality and productivity of the organization. Self-service is a decisive factor for care workers to demonstrate job competence, and self-leadership with expertise and autonomy can help provide quality services and increase productivity. Therefore, it is recommended that home-based elderly welfare center directors develop and apply a self-leadership improvement program as a way to improve the job commitment and job competence of care workers in charge of home-visit care.

Based on the results of this study, it is necessary to increase self-leadership in order to increase the job competence of care workers in charge of home-visit care. In order to do that, one must control oneself and increase self-motivating autonomy, and knowing one's role and abilities with thinking and action strategies, setting goals and putting them into practice, one should make an effort to take responsibility for the results. Ultimately, these efforts can increase the influence of care workers, and it is thought that they can improve their job competence and increase the satisfaction of the care recipients. Therefore, it is suggested that a leadership improvement program be developed and actively used as supplementary education for care workers.

Ethical Clearance: Not required

Source of Funding: Self

Conflict of Interest: Nil

\section{References}

1. Jung, KH. et al. A Survey on the Status of the Elderly in 2017. Korea Institute for Health and Social Affairs. 2017, November. https://www.kihasa.re.kr/ web/publication/research/view.do?pageIndex $=15$ $\&$ keyField $=\&$ key $=\&$ menuId $=45$ \& tid $=71$ \& bid $=12$ \& division=002 \& ano=2298.

2. Kim, KW. A Study on the Relationship between Self-directed Learning Time and Job Competence, Focused on HRD Jobs. Korean Public Management Review. 2013;27(1):203-235.

3. Ra, MJ., Mo, SH. The Effects of Interpersonal Relationships on Job Satisfaction of Home-visiting Care Helpers. The Journal of Korea Contents Association. 2015;15(4):234-245.
4. Kim, HK. Lee NY., Park, CH. Effects of Selfefficacy and Wisdom on Job Competence of Care Workers in Korea. Medico-Legal Update. 2020;20(2):724-728.

5. Kim, HK., Park, CH., Lee, NY. Effects of Health Perception, Generativity, and Wisdom on Job Competency of Korean Care Workers. MedicoLegal Update. 2020;20(2):718-723.

6. Park, KH. The Effect of Job Education Satisfaction and Leaders' Coaching Behavior on Job Commitment in Securities Companies. Korea University, Master thesis, 2013.

7. Jung, SH. Relationship among Emotional Intelligence, Communication Ability, SelfLeadership and Teacher Competency of Day Center Teachers. Kookmin University, Master thesis, 2017.

8. Ann, JS. A Study on the Mediating Effects of Career Orientation in the Relationship between Manager's Power Type Level and HRD Officer's Job Commitment. Korea University, Master thesis, 2011.

9. Lee, JY. Prediction of Learning Transfer by Self-Efficacy, Organizational Support, and Job Relationship in Online Job Education. Ewha Womans University, Master thesis, 2012.

10. Mesurado, B., Richaud de Minzi, MC. Child's Personality and Perception of Parental Relationship as correlates of Optional Experience. Journal of Happiness Studies. 2013;14(1):199-214.

11. Manz, CC. Sims, HP. Super-leadership. New York: Prentice Hall, 1989.

12. Jeong, JH. Relation between Self-Leadership of Child Teacher and Teaching Practices. Dongeui University, Doctoral dissertation, 2012.

13. Koh, HI. The Impact of Employees' Self-Leadership on the Service Quality in Medical Institutions: Mediating Effect of Psychological Empowerment and Organizational Citizenship Behavior. Ulsan University, Doctoral dissertation, 2011.

14. Lee, J. Learning Transfer and Job Competence of Care Workers': Focusing on Dementia job training program participants, Gachon University, Doctoral dissertation, Seongnam, 2017.

15. Kim, AR. Impacts of Care Worker's Self-efficacy and Stress-coping Ability on Job Competency: 
Focus on female Care Workers providing Home Care Services in the C Region. Korea Nazarene University, Master thesis, 2019.

16. Park, SJ. The Influence of Low-Cost Carrier Cabin Crew's Job Competency on Job commitment and
Turnover Intention. Hanseo University, Master thesis, 2018.

17. Kim, KO. A Study on the Self-leadership Mediating Effect and the Occupational Identity moderating 